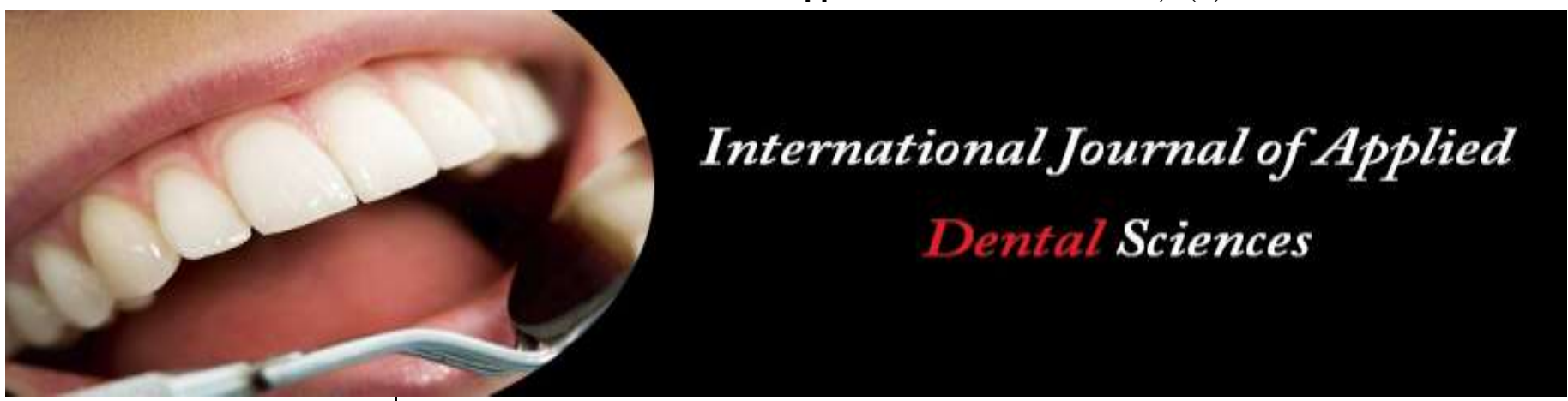

ISSN Print: 2394-7489

ISSN Online: 2394-7497

IJADS 2021; 7(2): 74-78

(C) 2021 IJADS

www.oraljournal.com

Received: 05-01-2021

Accepted: 26-02-2021

Dr. Ranjith Kumar P Associate Professor,

Department of Dentistry, Government Medical College,

Palakkad, Kerala, India

Dr. Sivaprasad KK

Assistant Professor,

Department of Dentistry, Government Medical College,

Palakkad, Kerala, India

Dr. Anila Karunakaran

Professor, Department of

Dentistry, Government Medical

College, Palakkad, Kerala, India

Corresponding Author: Dr. Ranjith Kumar P Associate Professor,

Department of Dentistry, Government Medical College,

Palakkad, Kerala, India

\section{Comparative evaluation of bond strength of denture base resin to acrylic resin teeth following different surface treatments: An In vitro study}

\author{
Dr. Ranjith Kumar P, Dr. Sivaprasad KK and Dr. Anila Karunakaran
}

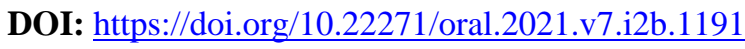

\section{Abstract}

Acrylic resin denture base material has been available to the dental profession for over 60 years, and although materials with superior properties have been on the market for some time, it still remains the most popular choice of clinicians. The requirement of the simple processing equipment and low cost of the fabrication process are the reasons for its continued popularity. However, debonding of acrylic teeth from denture base resins remains a problem for both patients and clinicians. The failure rate of acrylic dentures resulting from fracture has been reported to be unacceptably high, with the most prevalent type of failure documented being debonding or fractures of the teeth A series of studies have attempted to determine the quality of denture tooth bonding produced by commonly employed dental laboratory conditions. The present study was under taken to evaluate and compare the effects of chemical and mechanical treatment of the ridge lap surface of acrylic teeth on the bond strength of acrylic resin teeth to denture base resins.

Keywords: Bond strength, denture base resins, acrylic resin teeth

\section{Introduction}

Natural tooth loss is a matter of great concern to majority of people and their replacement by artificial substitutes, such as dentures is vital to the continuance of oral health. Any damage to the prosthesis subjects the patient to immense psychological stress. Conventionally, heat curing is used as the mode of polymerization for acrylic resins. Prefabricated acrylic resin teeth for dentures were introduced in 1940. Apart from the advantage of time saving, ease of fabrication and economy, these teeth bond chemically to the denture base material and have a life like translucent quality, even in thin sections of less than $1 \mathrm{~mm}$. Adequate bonding of acrylic resin teeth to the denture base resin is necessary because it increases stiffness and strength since the teeth become an integral part of the prosthesis. For an effective chemical bond, the polymerizing denture base resins must come into direct physical contact with the denture teeth resin and the polymer network of the denture base resins must react chemically with the denture tooth resin polymer to form an interwoven polymer network ${ }^{[1]}$. Foreign materials like wax remnants, tin foil substitute used as mold separating agent may interfere with the direct physical contact between the polymerizing denture base resins and the denture teeth resin, thereby adversely affecting the bond strength ${ }^{[2]}$. In a bid to solve the problem of teeth debonding from the denture bases, various studies ${ }^{[3,4]}$ have been made to improve the bond strength by chemical or mechanical preparation of the denture teeth prior to bonding.

Huggert R, John G, Jagger R G et al. ${ }^{[5]}$ in 1982 tested the bonding potential of three types of anterior plastic teeth, each having varying degrees of copolymerization with a heat cured and an autopolymerizing resin. Teeth as supplied by the manufacturer, were compared to those where the ridge lap surface were modified by Grinding, Grinding and re-polishing, Cutting a retention groove. The specimens were prepared and tested in a tensile-shear mode in batches of six, with a crosshead speed of $5 \mathrm{~mm} / \mathrm{min}$. It was reported that the ridge lap modification failed to improve the strength of the bond between the teeth and the denture base resins. 
Catterlin R K, Plummer K D, and Gulley M E [6] in 1993 studied effect of tin foil substitute contamination on bond strength. Eighty maxillary right central incisors were bonded with Lucitone denture base material. After wax elimination Tin foil substitute was carefully applied to the plaster avoiding contact with the denture teeth (Control group) Tin foil substitute applied to both the plaster and the denture teeth (Experimental group).The study concluded that contamination of acrylic resin denture teeth with tin foil substitute significantly reduced the bond strength.

Cardash H S, Liberman R and Helft $\mathrm{M}^{[7]}$ in 1986 investigated the effect of cutting retention grooves in the tooth ridge lap area on the bond strength. 60 central incisor teeth of the same mold were bonded with one brand of heat cured denture base resin. Specimens were divided in four groups:

Group A - No preparation

Group B-Groove $2 \mathrm{~mm}$ deep and $2 \mathrm{~mm}$ wide with straight fissure bur

Group C - Groove $2 \mathrm{~mm}$ deep and $2 \mathrm{~mm}$ wide with inverted cone bur

Group D - Half round groove $2 \mathrm{~mm}$ in diameter with a round bur.

Triangular shaped models with teeth bonded to two sides were used for the study. A vertical compressive shear load was applied at a rate of $5 \mathrm{~mm} / \mathrm{min}$ at an angle of 130 degrees to the long axis of each tooth.No statistically significant advantage was derived by preparing retention grooves of different shape in the ridge lap surface of the denture teeth.

Spartley M H ${ }^{[8]}$ in 1987 investigated the effect of contamination by wax, petroleum jelly and sodium alginate on the bond strength. Acrylic and porcelain teeth of identical size and shape were used for the study. Wax was eliminated by flushing the flask with hot water in a wax elimination machine and sodium alginate applied as cold mold seal.

Contamination with petroleum jelly and sodium alginate solution did not affect the adhesion. Wax was found to be the principal contaminant and a cause for adhesive failure.

Takahashi Y et al. ${ }^{[9]}$ in 2000 investigated the bond strength of denture teeth with denture base resins. The denture teeth were untreated, prepared with diatorics, or treated with dichloromethane. The denture base materials used in the study were heat cured, micro-wave cured and a pour type of resin.. The bond strength between the denture teeth and denture base resins was improved by the preparation of a diatoric on the palatal aspect of the teeth. Treatment of the ridge lap surface of the teeth with dichloromethane further enhanced the bond strength.

The present study was under taken to evaluate and compare the effects of chemical and mechanical treatment of the ridge lap surface of acrylic teeth on the bond strength of acrylic resin teeth to denture base resins.

\section{Aims and Objectives}

- To evaluate the effect of mechanical treatment of ridge lap surface of acrylic resin teeth on the bond strength of acrylic resin teeth to denture base resins.

- To evaluate the effect of chemical treatment of ridge lap surface of acrylic resin teeth on the bond strength of acrylic resin teeth to denture base resins.

- To evaluate the effect of tin foil substitute contamination on the bond strength of acrylic resin teeth to denture base resins.

\section{Materials and Methods}

The materials used for the study are.
Prefabricated acrylic resin denture teeth: One brand (Premadent) of cross linked acrylic resin teeth were used in this study. In order to standardize the tooth size, only the maxillary central incisors of the same mould (P4) was used.

Denture base resin: $\mathrm{D}$ P I Heat cure improved polymethylmethacrylate denture base resin

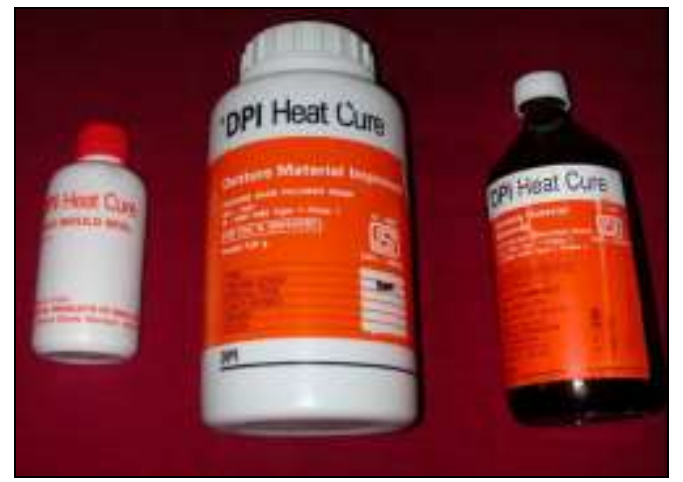

Fig 1: DPI Heat cure denture base resin

\section{Chemicals}

Methylmethacrylate monomer

Dichloromethane

DPI Cold Mold Seal

\section{Equipments}

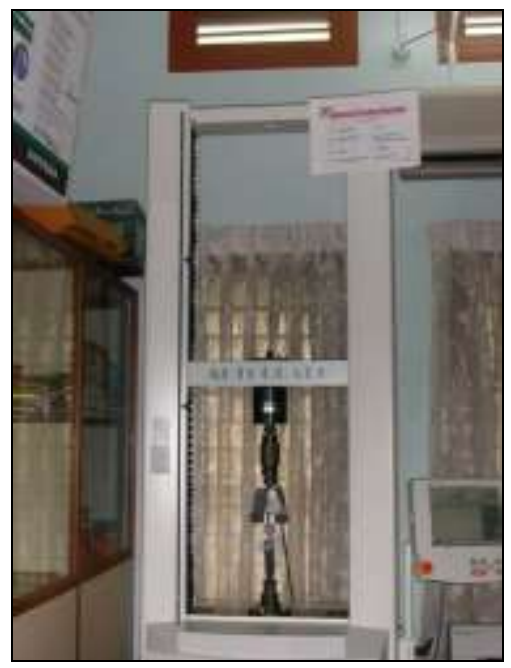

Fig 2: Universal Testing machine (Schimadzu Inc.)

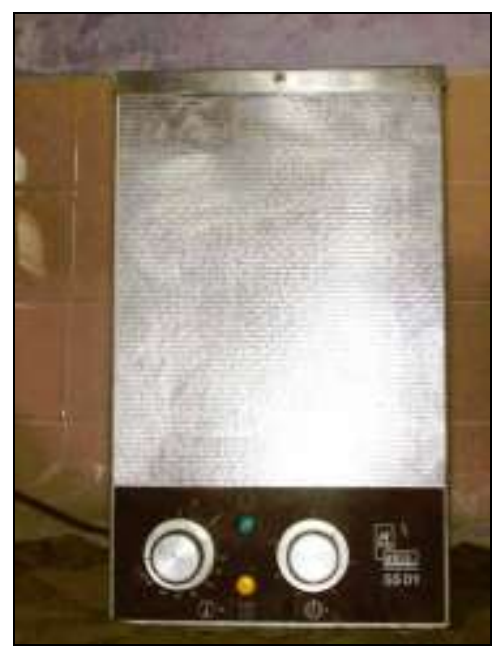

Fig 3: Acryliser (Kavo Inc.) 
A total of 48 teeth were used for the study. 48 teeth were distributed in 8 different groups with six samples in each group

Groups with no mechanical treatment of the ridge lap area

\begin{tabular}{|c|c|}
\hline Group I & Control group with tin foil contamination on the ridge lap area of acrylic resin teeth wiped off with dry cotton. \\
\hline Group II & Group with tin foil contamination of the ridge lap area. \\
\hline Group III & Group with tinfoil contamination followed by methylmethacrylate application on ridge lap area. \\
\hline Group IV & Group with tin foil contamination followed by dichloromethane application on the ridge lap area. \\
\hline
\end{tabular}

Groups with mechanical treatment of the ridge lap area

\begin{tabular}{|c|c|}
\hline Group V & Group with tin foil contamination on the ridge lap area of acrylic resin teeth wiped off with dry cotton. \\
\hline Group VI & Group with tin foil contamination of the ridge lap area. \\
\hline Group VII & Group with tinfoil contamination followed by methylmethacrylate application on ridge lap area. \\
\hline Group VII & Group with tin foil contamination followed by dichloromethane application on the ridge lap area. \\
\hline
\end{tabular}

\section{Methodology for the preparation of the test specimen}

Test specimens were prepared by aligning the long axis of the 6 teeth ( 3 on both sides) at 45 degrees to the sides of a rectangular wax block, which was contoured to a size of $70 \mathrm{X}$ $40 \times 10 \mathrm{~mm}$. For groups V to VIII the ridge lap area of the acrylic resin teeth were roughened with acrylic trimming stones to remove the glossy surface. The wax contacted only the ridge lap area of the teeth. The wax blocks were flasked in a conventional metal flask using dental plaster. Dewaxing was done by placing the flask in boiling water for 5 to 7 minutes and then flushed with running boiling water to remove the wax completely.

Tin foil substitute applied. For the control group tin foil substitute is carefully applied to the plaster, avoiding contact with denture teeth and the tin foil substitute present on the ridge lap area of the teeth is wiped off with dry cotton. After dewaxing, the ridge lap area of the acrylic resin teeth were lightly coated with methylmethacrylate monomer for groups III and VII, and dichloromethane for groups IV and VIII, 10 minutes prior to packing. The flasks were packed with improved heat cure denture base material following manufacturer's instructions. The flasks were allowed to bench cure for 30 minutes. Thermostatically controlled water bath was used for acrylisation. The test specimens were subjected to gradual heating by placing the flasks in water bath at room temperature to $65^{\circ} \mathrm{C}\left(159{ }^{0} \mathrm{~F}\right)$ for 90 minutes and then boiling at $100{ }^{\circ} \mathrm{C}$ for 1 hour. After completion of the polymerization cycle, flasks were bench cooled overnight at room temperature before deflasking. The test specimens were retrieved and minimal adjustments were attempted for final corrections. Acrylic resin surrounding the necks of the teeth, if any, was removed using acrylic trimming burs.

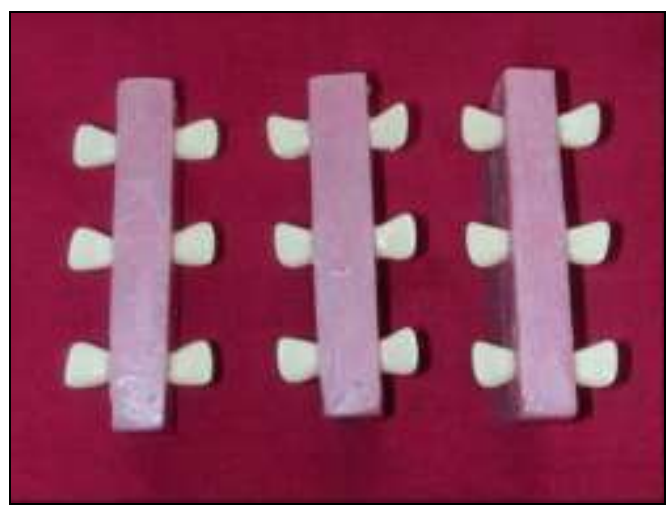

Fig 4: Test Specimens

\section{Testing of the Specimens}

The prepared specimens were subjected to load testing using a computer coordinated Universal Testing Machine (Schimadzu
Inc.). The test specimens were placed in the lower jaw of the load testing machine and a vertical rod mounted on the upper jaw of the Universal Testing Machine was aligned to apply load on the palatal aspect of the specimen denture teeth.

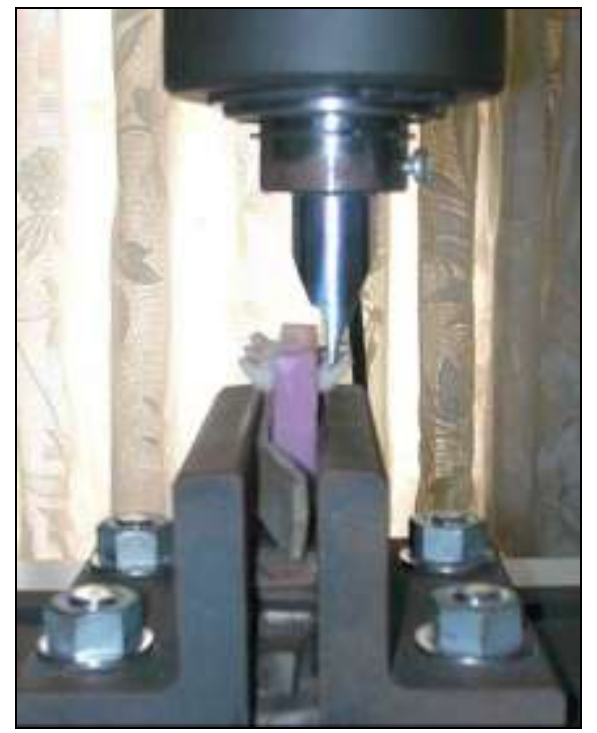

Fig 5: Test Specimen loaded in Universal Testing Machine

A crosshead speed of $0.5 \mathrm{~mm} / \mathrm{min}$ was used for testing the bond strength. Load was applied until the denture teeth separated from the denture base resin.

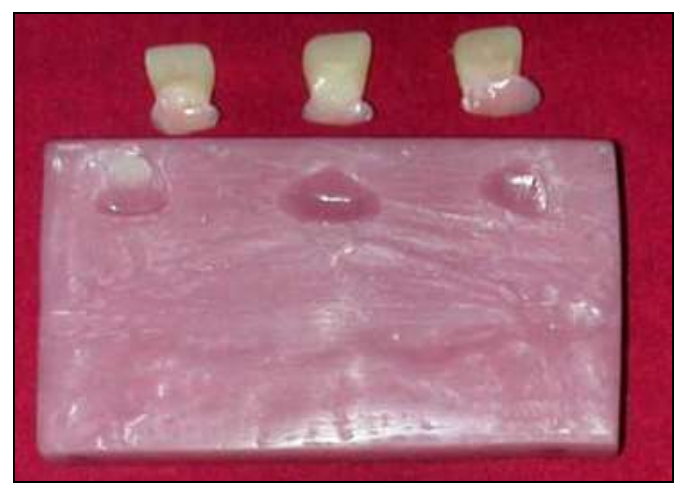

Fig 6: Specimens after testing

The computer attached to the Universal Testing Machine recorded the resulting bond strength values. The results were recorded and statistically analyzed.

\section{Results}

The mean bond strength of acrylic resin teeth without any mechanical treatment ranged from $256.1098 \mathrm{~N}$ to $321.915 \mathrm{~N}$ 
(Table-1), where as those with mechanical treatment of the ridge lap area of acrylic resin teeth varied from $270.196 \mathrm{~N}$ to
425.334 N (Table-2)

Table 1: Mean tensile bond strength of specimens without mechanical treatment

\begin{tabular}{|c|c|c|c|c|}
\hline & Group I & Group II & Group III & Group IV \\
\hline Sample 1 & 270.675 & 236.265 & 336.843 & 309.546 \\
\hline Sample 2 & 313.983 & 243.843 & 315.585 & 339.218 \\
\hline Sample 3 & 265.953 & 254.968 & 355.734 & 326.265 \\
\hline Sample 4 & 284.484 & 231.568 & 273.718 & 271.796 \\
\hline Sample 5 & 256.906 & 290.703 & 283.89 & 287.359 \\
\hline Sample 6 & 320.015 & 279.312 & 365.718 & 292.984 \\
\hline Mean & 285.336 & 256.11 & 321.915 & 304.528 \\
\hline Std. Deviation & 26.1646 & 24.012 & 37.6675 & 25.3002 \\
\hline Maximum & 320.015 & 290.703 & 365.718 & 339.218 \\
\hline Minimum & 256.906 & 231.568 & 273.718 & 271.796 \\
\hline Range & 63.109 & 59.135 & 92 & 67.422 \\
\hline
\end{tabular}

Table 2: Mean tensile bond strength of specimens with mechanical treatment

\begin{tabular}{|c|c|c|c|c|}
\hline & Group V & Group VI & Group VII & Group VIII \\
\hline Sample 1 & 343.453 & 243.968 & 445.781 & 410.468 \\
\hline Sample 2 & 338.156 & 318.296 & 424.046 & 381.406 \\
\hline Sample 3 & 406.124 & 247.468 & 466.515 & 384.609 \\
\hline Sample 4 & 347.781 & 284.406 & 392.406 & 402.281 \\
\hline Sample 5 & 388.187 & 254.203 & 419.634 & 391.031 \\
\hline Sample 6 & 340.515 & 272.832 & 403.624 & 423.754 \\
\hline Mean & 360.703 & 270.196 & 425.334 & 398.925 \\
\hline Std. Deviation & 28.979 & 28.2231 & 27.2165 & 16.3411 \\
\hline Maximum & 406.124 & 318.296 & 466.515 & 423.754 \\
\hline Minimum & 338.156 & 243.968 & 392.406 & 381.406 \\
\hline Range & 67.968 & 74.328 & 74.109 & 42.348 \\
\hline
\end{tabular}

Table 3: Results of Two-Way ANOVA (Analysis of Variance)

\begin{tabular}{|c|c|c|c|c|c|c|}
\hline & Df Effect & MS Effect & Df Error & MS Error & F & p-level \\
\hline Chemical & 3 & 27497.86 & 40 & 745.525 & 36.8838 & $1.35 \mathrm{E}-11$ \\
\hline Mechanical & 1 & 61892.54 & 40 & 745.525 & 83.0187 & $2.63 \mathrm{E}-11$ \\
\hline Interaction & 3 & 4854.084 & 40 & 745.525 & 6.51096 & 0.001084 \\
\hline
\end{tabular}

$\mathrm{df}$ - degrees of freedom, $\mathrm{F}-\mathrm{F}$ value

MS - Mean Sum of Square, p -level - Probabilities

Table 4: Probabilities (p-value) for Post Hoc Tests using Scheffe' Test

\begin{tabular}{|c|c|c|c|c|c|c|c|c|}
\hline & Group I & Group II & Group III & Group IV & Group V & Group VI & Group VII & Group VIII \\
\hline Mean Bond Strength & 285.3360 & 256.1098 & 321.9147 & 304.5280 & 360.7027 & 270.1955 & 425.3343 & 398.9248 \\
\hline Group I & & 0.835386 & 0.616348 & 0.980731 & 0.00774 & 0.995331 & $8.76 \mathrm{E}-08$ & $1.03 \mathrm{E}-05$ \\
\hline Group II & 0.835386 & & 0.032053 & 0.254045 & $5.25 \mathrm{E}-05$ & 0.997026 & $5.46 \mathrm{E}-10$ & $5.3 \mathrm{E}-08$ \\
\hline Group III & 0.616348 & 0.032053 & & \begin{tabular}{|l|}
0.989181 \\
\end{tabular} & 0.542142 & 0.182673 & $6.48 \mathrm{E}-05$ & 0.005974 \\
\hline Group IV & 0.980731 & 0.254045 & 0.989181 & & 0.111251 & 0.689837 & $2.79 \mathrm{E}-06$ & 0.000322 \\
\hline Group V & 0.00774 & $5.25 \mathrm{E}-05$ & 0.542142 & 0.111251 & & 0.000633 & 0.037719 & 0.561178 \\
\hline Group VI & 0.995331 & 0.997026 & 0.182673 & 0.689837 & 0.000633 & & 6.08 E -09 & $6.63 \mathrm{E}-07$ \\
\hline Group VII & $8.76 \mathrm{E}-08$ & $5.46 \mathrm{E}-10$ & $6.48 \mathrm{E}-05$ & $2.79 \mathrm{E}-06$ & 0.037719 & $6.08 \mathrm{E}-09$ & & 0.896047 \\
\hline Group VIII & $1.03 \mathrm{E}-05$ & $5.3 \mathrm{E}-08$ & 0.005974 & 0.000322 & 0.561178 & $6.63 \mathrm{E}-07$ & 0.896047 & \\
\hline
\end{tabular}

Bolded figures: $\mathrm{p}$-value $<0.01-$ Highly significant

Italic figures: p-value $<0.05$ - significant at $5 \%$ level

p-value $>0.05-$ Not significant

\section{Discussion}

The control group had mean bond strength of to $285.336 \mathrm{~N}$. The highest bond strength was noted for group III (with monomer application on ridge lap area) with mean bond strength of $321.915 \mathrm{~N}$ followed by group IV with a mean of $304.528 \mathrm{~N}$. The lowest bond strength was recorded for group II. Highest bond strength was noted for the group VII of 425.334 N followed by group VIII and group V in that order. The lowest strength was noticed for group VI with a mean value of 270.196 .

The Post-Hoc tests following Sheffe' tests shows statistically significant differences in the bond strength between Group I and Group V, which explains that roughening of the ridge lap area of the acrylic resin teeth increases the bond strength. This is also evident from the significant differences in the bond strength between the groups III and VII and groups IV and VIII. (Table-3)The increase in the bond strength following mechanical treatment of ridge lap area may be attributed to two reasons.

- The mechanical treatment of the ridge lap area of teeth increases the surface area on the denture teeth available for the polymerizing denture base resins to interact.

- The mechanical treatments aids in better penetration of the acrylic resin and also produce some surface 
irregularities into which the denture base resins flows in the dough stage during packing. This eventually provides mechanical retention following their polymerization.

The Two-Way ANOVA for comparison of variable shows that the interaction between mechanical treatment and chemical treatment to be highly significant (Table-4).

This means that the chemicals act differently on the acrylic resin teeth with and without mechanical treatment. The action of chemicals on the specimens with roughened ridge lap area is greater than on those with glossy ridge lap area. This is probably because the roughening of ridge lap area allows more penetration of the chemicals into the polymer network of teeth. There is no statistically significant difference in bond strength between groups I, II, III and IV which shows that the chemicals have less effect on glossy ridge lap surface. The significant difference in the bond strength of group VI with groups V, VII and VIII shows that tinfoil contamination of the ridge lap area significantly reduces the bond strength.

For an effective chemical bonding between the acrylic resin teeth and the denture base resins the polymerizing denture base resins must come into physical contact with the denture tooth resin and the polymer network of the denture base resin must react chemically with the denture tooth resin polymer to form an interwoven polymer network. The contamination with tin foil substitute used as a mold-separating agent interfere with the contact between the polymerizing denture base resin and the denture tooth resin thereby adversely affecting the bond strength.

Thean et al. ${ }^{[8]}$ in their studies in 1996 suggested that the removal of surface contaminants like cold mold seal wax remnants from the bonding surfaces of the denture tooth prior to packing is more important than mechanical preparation of the tooth surface.

There is significance at $5 \%$ level in the bond strength between groups V and VII, where as there is no significance difference between groups V and VIII, which shows that the application of methylmethacrylate monomer on the ridge lap area is more effective in increasing the bond strength, compared to dichloromethane. However the study also shows no much significance in the difference in bond strength between groups VII and VIII. Dichloromethane is a polymerisable solvent which facilitates the swelling of the denture tooth polymer and thereby enhancing the diffusion of the polymerisable methylmethacrylate monomer from the denture base resins. The application of methylmethacrylate monomer on the ridge lap area prior to packing aids in more penetration of the polymerisable monomer into the denture teeth polymer there by increasing the strength of interwoven polymer network. The methylmethacrylate applied on the ridge lap area also act by removing the surface contaminants like wax remnants and tin foil substitute used as cold mold seal, there by providing more physical contact between the polymerizing denture base resins and denture tooth resin.

\section{Conclusion}

From the study the following conclusions were drawn

- The mechanical treatment of the ridge lap area of acrylic resin teeth significantly increased the bond strength.

- The chemicals like methylmethacrylate monomer and dichloromethane are more effective in increasing the bond strength in roughened ridge lap surface when compared to glossy ridge lap surface.

- Application of methylmethacrylate monomer on roughened ridge lap area significantly increased the bond strength.

- Tin foil substitute contamination of the ridge lap area consistently reduced the bond rength in all the specimens with a significant reduction observed in mechanically treated specimens.

\section{References}

1. Anusavice KJ. Denture base resins: Technical considerations, miscellaneous resins and techniques. Philip's Science of Dental Materials, $10^{\text {th }}$ edition: W. B. Saunders Company, USA 237-272.

2. Craig RG. Prosthetic applications of polymers. Restorative Dental Materials. $10^{\text {th }}$ edition: Mosby-year book, USA 500-551.

3. Marra J, de Souza RF, Barbosa DB, Pero AC, Compagnoni MA. Evaluation of the bond strength of denture base resins to acrylic resin teeth: effect of thermocycling. J Prosthodont 2009;18:438-443.

4. Pande N, Zarekar S, Jaiswal P. Evaluation of shear bond strength of acrylic resin teeth to heat-polymerized denture base resin before and after thermocycling: An in vitro study. Indian J Multidiscip Dent 2018;8:25-32.

5. Hugget R, John G, Jagger RG, Bates JF. Strength of the acrylic denture base tooth bond. Br Dent J 1982;153:18790

6. Catterlin RK, Plummer KD, Gulley ME. Effect of tinfoil substitute contamination on adhesion of resin denture tooth to its denture base. J Prosthet Dent 1993;69:57-9.

7. Cardash HS, Liberman R, Helft $M$. The effect of retention grooves in acrylic resin teeth on tooth denturebase bond. J Prosthet Dent 1986;55:526-8.

8. Spratley MH. An investigation of the adhesion of acrylic resin teeth to dentures. J Prosthet Dent 1987; 58: 389-92

9. Takahashi Y, Chai J, Takahashi T et al. Bond strength of denture teeth to denture base resins. Int J Prosthodont. 2000;13(1):59-65.

10. Thean HP, Chew CL, Goh KI. Shear bond strength of denture teeth to base: a comparative study. Quintessence Int 1996;27(6):425-8. 